\title{
Which is better for pfannensteil skin incision closure in caesarean section? Interrupted mattress suture or continuous subcuticular suture
}

\author{
Shridevi A. S. ${ }^{1 *}$, Madhusoodana R. Bhovi ${ }^{2}$, Prema Prabhudeva ${ }^{1}$, Renuka ${ }^{1}$, Camelia Maitra ${ }^{1}$
}

${ }^{1}$ Department of Obstetrics and Gynecology, SSIMS and RC, Davanagere, Karnataka, India

${ }^{2}$ Consultant Anesthesiologist, Davanagere, Karnataka, India

Received: 23 June 2020

Accepted: 31 July 2020

\section{*Correspondence:}

Dr. Shridevi A. S.,

E-mail: asshridevi@yahoo.com

Copyright: (c) the author(s), publisher and licensee Medip Academy. This is an open-access article distributed under the terms of the Creative Commons Attribution Non-Commercial License, which permits unrestricted non-commercial use, distribution, and reproduction in any medium, provided the original work is properly cited.

\begin{abstract}
Background: Caesarean delivery is one of the most commonly performed operations in obstetrics. Postoperative comfort of the woman largely depends on the method of skin closure. Wound complications from caesarean delivery such as dehiscence or infection cause a significant emotional and economic burden in obstetric care. There are many methods and techniques for skin wound closure in caesarean section. Each technique has its own advantages and disadvantages. The aim and objective of this study was to compare the wound outcomes in Pfannensteil incisions closed with mattress sutures using nonabsorbable suture and subcuticular sutures using absorbable sutures in caesarean deliveries.

Methods: It is a prospective observational study done on 216 consecutive pregnant women who were admitted to labor room for elective or emergency caesarean section. Patients undergoing caesarean section with Pfannensteil incision between February 2019 to October 2019 were included in this study. Among 216 women, 108 women had mattress sutures and 108 women had subcuticular sutures for skin wound closure. The primary outcome studied was wound complications including erythema, wound dehiscence, burst abdomen, infection and pain which was studied on postoperative day 3-7. The secondary outcome was assessed at 6 weeks follow-up in terms of pain, cosmetic appearance of scar and patient satisfaction about scar.

Results: A total of 216 pregnant women undergoing caesarean section were studied who had similar baseline characteristics and risk factors. However, women with previous caesarean section were more in mattress group. The overall incidence of erythema, surgical site infection, wound dehiscence, resuturing and pain was more in mattress group and was statistically significant. During follow-up at 6 weeks, women with subcuticular sutures had cosmetically better scar and more satisfied with their scars than women with mattress sutures but the pain level was same in both groups.

Conclusions: Authors conclude that compared to mattress sutures, subcuticular sutures cause significantly fewer wound complications and pain in postoperative period. Also, subcuticular sutures are associated with cosmetically appealing scars and higher patient satisfaction. But there was no difference in pain level at 6 weeks in both methods of skin closure.
\end{abstract}

Keywords: Caesarean section, Mattress sutures, Subcuticular sutures, Suture materials, Wound healing

\section{INTRODUCTION}

Caesarean delivery is one of the most commonly performed operations today. As medical science and especially obstetrics has evolved over the recent years, there has been a parallel and steady increase in the rate of caesarean births. Though caesarean delivery can be performed by both vertical skin incision and transverse skin incision, of late transverse skin incisions have almost 
replaced the vertical incisions. Vertical skin incision is reserved only for few indications.

There are many types of transverse abdominal incisions viz., the Pfannensteil, the Joel-Cohen, Maylard's and Cherney's incision. ${ }^{1}$ Transverse skin incisions are less painful, allow early postoperative ambulation and are associated with a lower risk of subsequent herniation and yet provide equal, if not better visualization of pelvis. ${ }^{2}$ Nowadays, majority of caesarean deliveries are performed by Pfannensteil incision. Pfannensteil incision was first described and performed by Pfannensteil in $1897 .{ }^{3}$ It is a low transverse, curvilinear incision made at a point approximately $3 \mathrm{~cm}$ above the pubic symphysis.

Following caesarean section, subsequent apposition of skin edges is important for wound healing by primary intention and to reduce postoperative morbidities. Although the outcome of surgical skin closure may be influenced by the indication for the procedure, the location of the surgical site, intraoperative and postoperative complications, it also depends on the technique and method of skin closure. The goal of any skin closure technique is to produce appropriate skin approximation and adequate healing with minimal wound complications, scarring, pain and cost. ${ }^{4}$

Given the trend of rising caesarean section rate, wound complications such as disruption or infection, remain an important cause of post caesarean morbidity at considerable costs to the patient and health system. ${ }^{5}$ As the rate of caesarean delivery increases, so does the associated complications. Following caesarean delivery, wound complications occur in $2.5 \%-16 \%$ of cases. $^{6}$

Wound healing is a combination of events that occur in a careful synchronous order. The steps that occur are initiated by a variety of cell secreted factors such as cytokines which direct the function of other cells. Wound healing occurs in 3 phases, inflammatory phase, proliferative phase and remodelling phase. Skin healing with restoration of epithelium without fibrosis takes place by primary intention, in the absence of infection, haematoma formation or other wound complications. ${ }^{7}$

Many techniques and suture materials have been tried to achieve closure and restore the structural and functional anatomy of skin. ${ }^{8}$ The methods for skin closure at caesarean section include subcuticular sutures with absorbable and nonabsorbable suture materials, interrupted mattress sutures, metal staples, absorbable staples, adhesive closure strips and tissue adhesives. ${ }^{9}$ An ideal wound closure device or technique should be easy to use, fast, painless, should provide excellent cosmetic appearance and be cost effective; no wound closure technique is ideal for all situations and the physician decides which method suits that particular patient. ${ }^{10}$

Materials and techniques used for skin closure influences the quality of wound outcomes in terms of postoperative pain, induration, infection, healing, cosmetic appearance and wound acceptance by patient. ${ }^{11}$

Suture materials are required to keep the wound together until they hold sufficiently well by themselves by natural fibre (collagen) to form a strong scar. Different suture materials produce varying degrees of tissue reaction, specifically inflammation. Best ways to close skin incisions for optimal results are still under experimentation. A good suture material is the one which causes the least foreign body reaction and inflammation. A good surgical technique is the one that eliminates the dead space in subcutaneous tissue and approximates edges without tension. ${ }^{9}$ However, Cochrane review by Alderdice et al concluded that there was no conclusive evidence in the choice of techniques and materials to use at skin closure at caesarean section. ${ }^{12}$ A subcuticular suturing involves repairing the subcuticular or epidermal tissue in a running suture. The resultant scar is linear, thin and cosmetically more acceptable. ${ }^{13}$ If an absorbable suture is used, it can be left in place eliminating the need for suture removal, facilitating the early discharge from the hospital. Vertical mattress suture involves piercing the skin at four points at the same level for a single stitch, gathers a good amount of subcuticular tissue and fat in a tight stitch and leaves gaps between the sutures to allow drainage of blood and serosanguineous discharge from fat necrosis. ${ }^{8}$ Mattress sutures obliterates the dead space and provides increased wound strength but disadvantages include difficulty in approximating wound edges and prominent suture marks leading to thick scars. ${ }^{14}$

This study was aimed to compare the wound outcomes in two widely used skin closure techniques - subcuticular sutures and mattress sutures for Pfannensteil incision closure in caesarean section.

\section{METHODS}

It is a prospective observational study done on pregnant women who were admitted to labor room for elective or emergency caesarean section during the period from February 2019 to October 2019. A total of 300 pregnant women with viable pregnancies greater than 28 gestational weeks undergoing elective or emergency, first or repeat caesarean delivery with Pfannensteil incision were screened for this study.

\section{Inclusion criteria}

Patients undergoing caesarean section with Pfannensteil skin incision and skin closure done with either mattress or subcuticular sutures are included in this study.

\section{Exclusion criteria}

Obese women (BMI >30), history of allergy for antibiotics and analgesics, previous keloid formation or hypertrophic scar, chronic steroid use and presence of any immunological disorder. Patients not consenting for 
the study and patients who underwent non routine procedure (midline skin incision, postpartum hysterectomy or relaparotomy) because of an unexpected complication were also excluded.

Out of 300 women, 216 women were enrolled into this study. Among 216 women, 108 women had mattress sutures and 108 women had subcuticular sutures for skin wound closure. The primary outcome studied were wound complications including erythema, dehiscence, burst abdomen, wound infection and pain which was studied on postoperative day 3-7. The secondary outcome was studied at 6 weeks follow-up in terms of pain, cosmetic appearance of scar and patient satisfaction about scar.

The study was approved by the institutional ethical committee. Informed consent was obtained from all patients. Detailed history of the patient was taken and complete medical and obstetrical examination done as per our department protocol. After obtaining written consent, eligible women were enrolled into study. The authors did a prospective, observational, comparative study at SS Institute of Medical sciences and Research Centre, Davanagere, Karnataka, India.

The patients had routine preoperative preparation and all patients had caesarean section following standard technique and prophylactic perioperative antibiotics was given to all patients. The rectus sheath was closed using number 1 delayed absorbable suture, polygalactin 910 (vicryl). The skin incision was closed with either vertical mattress sutures or subcuticular sutures depending on consultant obstetrician's choice.

In mattress suture group, interrupted vertical mattress sutures are placed in "far-far-near-near" order of bites with nonabsorbable suture, nylon 2-0. (ETHILON R). The far loop enters and exits the skin surface at $90^{\circ}$ angle and passes deep into dermis including the whole of fat layer. ${ }^{15}$ Fat layer was not sutured separately.

In subcuticular suture group, skin was closed with subcuticular suture using poliglecaprone 25 (MONOCRYL - 3-0). Subcutaneous fat layer was sutured if it was more than $2.5 \mathrm{~cm}$ thick. Sterile dressing was done following skin closure in both groups.

All patients were assessed daily after surgery until discharge from the hospital and again at 6 weeks. Dressing was opened on $3^{\text {rd }}$ postoperative day and was left open. Mattress sutures were removed on postoperative day 7 to 10 . In subcuticular suture group, suture edges were cut on postoperative day 5 to 7 . All patients included in the study were advised not to use any medication that would affect wound healing. They were given analgesics as per hospital protocol.
A standardized physical examination of the wound was performed by the consultant obstetrician at postoperative day 3-7 and again at follow-up at 6 weeks.

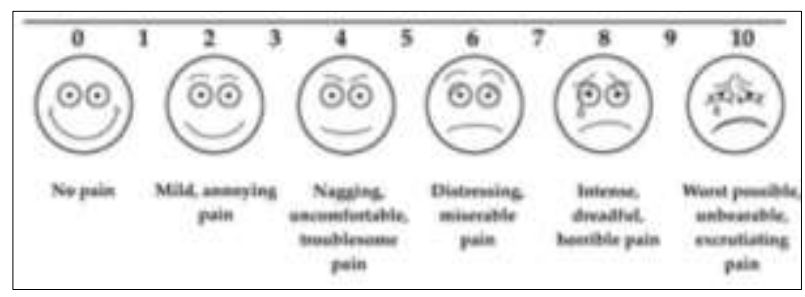

Figure 1: Visual analogue scale.

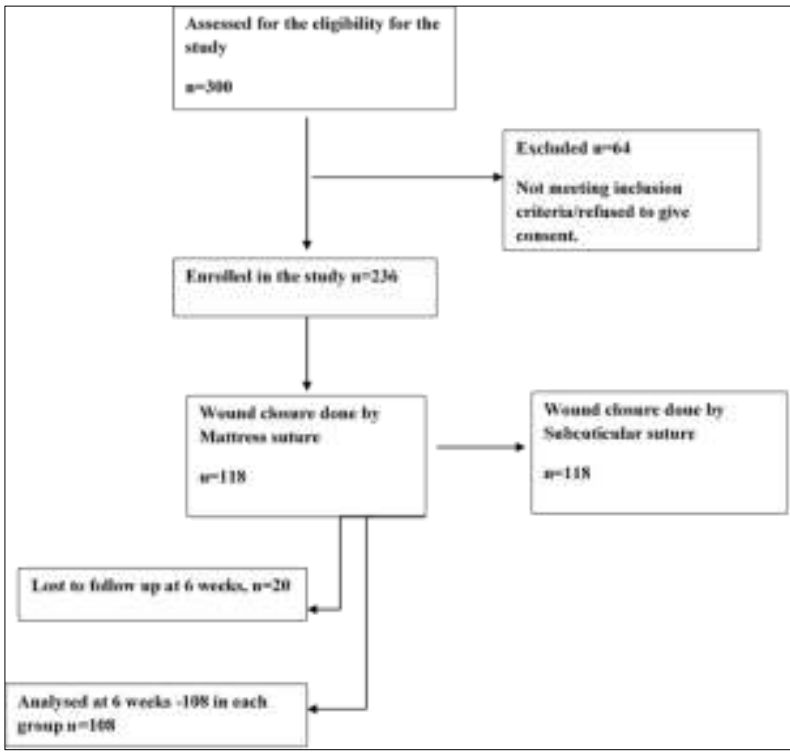

Figure 2: The flow of the participants through the study.

At day 3-7, primary outcomes related to wound healing like erythema, discharge (serosanguineous/purulent), pain, wound dehiscence, surgical site infection were assessed. Wound dehiscence was further divided into superficial $(<3 \mathrm{~cm})$, deep $(>3 \mathrm{~cm})$ and burst abdomen (i.e., fascial dehiscence). Wound infection was defined as purulent discharge, cellulitis, abscess, or wound requiring drainage, debridement and additional antibiotics for a clinical diagnosis of infection. Pain was assessed using visual analogue scale as shown in Figure $1 .^{16}$

At 6 weeks follow-up, secondary outcomes were assessed. Pain, cosmetic appearance of scar and patient satisfaction about scar were the parameters. Pain was assessed using visual analogue scale. Cosmetic appearance was graded by using these parameters. No scar or just a line, mild ridge with minimal change in colour and presence of a severe scar $(>0.5 \mathrm{~cm}$ ridge and red in colour). Overall patient satisfaction about scar was assessed using a 0-10 points visual analogue scale (VAS). 0 represented "not at all satisfied" and 10 "very satisfied". 


\section{Statistical analysis}

Data were analyzed using the SPSS version 17. Descriptive statistics (means, standard deviation, frequencies) were used to summarize the maternal characteristics. The student t-test and Chi-square test were employed in the evaluation of categorical data. $\mathrm{P}$ value $<0.05$ was considered statistically significant.

\section{RESULTS}

A total of 300 pregnant women scheduled for elective/emergency caesarean section were screened for this study. 64 women were excluded as some of them refused to give consent and some of them did not meet the inclusion criteria. Among the 236 women recruited, 20 were lost to follow-up and these were excluded from the analysis. 216 women completed the study and 108 women were analysed in each study group. The flow of the participants through the study is shown in Figure 2. The wound was assessed between postoperative day 3-7 and again at 6 weeks.

Table 1 shows the baseline characteristics of the participants. There was no statistically significant difference in terms of age and body mass index (BMI) in both groups.
Table 2 shows the distribution of risk factors. The incidence of anaemia, diabetes was equally distributed and not significant statistically. However, patient with one previous caesarean section and more than one previous caesarean were more in women with mattress suture (22.2\% and $14.8 \%$ respectively) than in women with subcuticular group ( $11.1 \%$ and $5.5 \%$ respectively). This was also statistically significant. $\mathrm{P}$ value was 0.044 and 0.042 respectively.

Table 3 shows the result of wound assessment done on postoperative day 3-7 (primary outcome). There were significant differences among two groups with respect to the parameters like erythema, wound dehiscence, surgical site infection and resuturing. The incidence of erythema was more in mattress group $(48.1 \%)$ than in subcuticular groups $(25.9 \%)$. P value being 0.001 and is statistically significant. Overall wound dehiscence was more in patients with mattress suture compared to subcuticular sutures $(14.8 \%$ versus $5.5 \%, \mathrm{p}$ value 0.02$)$. $11.1 \%$ of women with mattress suture and $5.5 \%$ of women with subcuticular suture had superficial wound dehiscence. Deep wound dehiscence $(1.8 \%)$ and burst abdomen $(1.8 \%)$ was seen only in patients with mattress sutures. The occurrence of infection and resuturing was also more in mattress (40.7\% and $21.2 \%$ ) than in subcuticular group (18.5\% and $7.4 \%)$, p value being 0.0006 and 0.0065 respectively and is statistically significant.

Table 1: Baseline characteristics of the participants.

\begin{tabular}{|llll|}
\hline & Mattress suture $(\mathbf{n}=\mathbf{1 0 8})$ & Subcuticular suture $(\mathbf{n = 1 0 8})$ & P value \\
\hline Age $($ Mean \pm SD) & $28.4 \pm 4.2$ & $26.4 \pm 4.9$ & 0.63 \\
\hline BMI $>\mathbf{1 9}$ & $30(27.7)$ & $24(22.2)$ & 0.43 \\
\hline BMI $<\mathbf{1 9}$ & $12(11.1)$ & $18(16.6)$ & 0.32 \\
\hline
\end{tabular}

Table 2: Risk factors.

\begin{tabular}{|llll|}
\hline & Mattress suture $(\mathbf{n = 1 0 8})$ & Subcuticular suture $(\mathbf{n = 1 0 8})$ & P value \\
\hline Anemia & $26(24.07)$ & $20(18.5)$ & 0.40 \\
\hline Diabetes & $12(11.1)$ & $16(14.8)$ & 0.54 \\
\hline One previous LSCS & $24(22.2)$ & $12(11.1)$ & 0.044 \\
\hline $\begin{array}{l}\text { More than one previous } \\
\text { LSCS }\end{array}$ & $16(14.8)$ & $6(5.5)$ & 0.042 \\
\hline
\end{tabular}

Table 3: Wound assessment on postoperative day 3-7 (primary outcome).

\begin{tabular}{|llllll|}
\hline & Mattress suture & \multicolumn{2}{c}{ Subcuticular suture } & P value \\
\hline Parameters & $\mathbf{n = 1 0 8}$ & $\mathbf{\%}$ & $\mathbf{n = 1 0 8}$ & $\mathbf{\%}$ & 0.001 \\
\hline Drythema & 52 & 48.1 & 28 & 25.9 & 0.07 \\
\hline Serosanguineous & 20 & 18.5 & 10 & 9.2 & 0.12 \\
\hline Purulent & 16 & 14.8 & 8 & 1.8 & 0.67 \\
\hline Wound dehiscence & 4 & 3.7 & 2 & 5.5 & 0.02 \\
\hline Superficial & 16 & 14.8 & 6 & 5.5 & 0.12 \\
\hline Deep & 12 & 11.1 & 6 & 0 & 0.72 \\
\hline Burst abdomen & 2 & 1.8 & 0 & 0 & 0.72 \\
\hline Infection & 2 & 1.8 & 0 & 18.5 & 0.0006 \\
\hline Resuturing & 44 & 40.7 & 20 & 7.4 & 0.0065 \\
\hline
\end{tabular}

Continued. 


\begin{tabular}{|lllll|}
\hline Parameters & Mattress suture & \multicolumn{2}{c|}{ Subcuticular suture } & P value \\
\cline { 2 - 3 } & $\mathbf{n = 1 0 8}$ & $\mathbf{\%}$ & $\mathbf{n = 1 0 8}$ & \% \\
\hline Postoperative pain $($ VAS $)$ & & & \\
\hline Mean \pm SD & $7.2 \pm 0.99$ & & $4.3 \pm 0.68$ & 0.039 \\
\hline Median $\left(25^{\text {th }}\right.$ to $\left.75^{\text {th }}\right)$ & $7(4-8)$ & & $4(3-6)$ & \\
\hline
\end{tabular}

Table 4: Wound assessment at 6 weeks (secondary outcome).

\begin{tabular}{|c|c|c|c|c|c|}
\hline \multirow{2}{*}{ Parameters } & \multicolumn{2}{|c|}{ Mattress group } & \multicolumn{2}{|c|}{ Subcuticular group } & \multirow[t]{2}{*}{ P value } \\
\hline & $\mathrm{n}=108$ & $\%$ & $\mathrm{n}=108$ & $\%$ & \\
\hline \multicolumn{6}{|l|}{ Pain (VAS) } \\
\hline Mean \pm SD & $4.3 \pm 0.68$ & - & $3.2 \pm 0.99$ & - & \multirow{2}{*}{0.78} \\
\hline Median $\left(25^{\text {th }}-75^{\text {th }}\right)$ & $3(2-6)$ & - & $3(1-5)$ & - & \\
\hline \multicolumn{6}{|l|}{ Cosmetic appearance } \\
\hline No scar or just a line & 42 & 38.8 & 62 & \multicolumn{2}{|l|}{57.4} \\
\hline Mild ridge with minimal change in color & 56 & 51.8 & 42 & \multicolumn{2}{|l|}{38.8} \\
\hline Severe scar $(0.5 \mathrm{~cm}$ ridge and red in color & 10 & 9.2 & 4 & \multicolumn{2}{|l|}{3.7} \\
\hline \multicolumn{6}{|l|}{ Satisfaction } \\
\hline Mean \pm SD & $7.1 \pm 0.75$ & - & $3.5 \pm 0.71$ & - & \multirow{2}{*}{0.038} \\
\hline $\operatorname{Median}\left(25^{\text {th}}-75^{\text {th }}\right)$ & $7(6-8)$ & - & $3(2-6)$ & - & \\
\hline
\end{tabular}

Postoperative pain as assessed by visual analogue scale (VAS) was more in mattress (7.2 \pm 0.99$)$ than subcuticular (4.3 \pm 0.68$)$ group. $\mathrm{P}$ value being 0.039 and statistically significant.

When patients came for postoperative follow-up at 6 weeks, patients were assessed in terms of pain, cosmetic appearance and about patient satisfaction about scar and these results are shown in Table 4.

The cosmetic appearance was better in patients with subcuticular suture as majority $(57.4 \%)$ had no scar or just a line when compared to mattress (38.8\%). 9.2\% patients had severe scar in mattress as compared to only $3.7 \%$ in subcuticular group. Overall patient satisfaction was higher among subcuticular group than mattress group, p value being 0.038 and is statistically significant. However, postoperative pain score at 6 weeks by VAS was similar in both groups and was not statistically significant.

\section{DISCUSSION}

Functional and cosmetic aspects of caesarean deliveries are gaining increasing importance in recent years. There is still a lack of data in terms of the best method for skin closure in caesarean operations. ${ }^{9}$ Pfannensteil incision is widely used for caesarean sections as it gives more comfort postoperatively and is cosmetically acceptable to patients.

Main aim of any skin closure technique is to produce appropriate approximation which helps in adequate healing. It should also cause minimal pain and scarring and less wound complications. The technique should be faster, cost effective and have maximum cosmesis and patient satisfaction. ${ }^{5}$ However, the technique of skin closure with best outcome for caesarean section is poorly studied and the best method for skin closure in caesarean section is unknown at present. ${ }^{10,12}$

In this prospective, observational study, authors describe the outcomes of 2 commonly used skin closure techniques, i.e., mattress sutures using nonabsorbable suture and subcuticular suture using delayed absorbable suture in caesarean section. The two study groups were comparable for baseline characteristics like age, BMI, and risk factors like anaemia and diabetes. The operative wound was assessed at 2 stages, first between 3-7 postoperative days and second at 6 weeks follow up. Women with previous one caesarean section and more than one caesarean section were more in mattress suture group $(22.2 \%$ and $14.8 \%$ respectively) than in subcuticular suture group (11.1\% and $5.5 \%$ respectively). This is comparable with the study done by Vasudev et al. ${ }^{14}$ It was observed that surgeons opted for mattress sutures in women with previous caesarean section which showed a selection bias.

This study showed that erythema was more in mattress suture group $(48.1 \%)$ than subcuticular suture group $(25.9 \%)$. There was no significant difference among the 2 groups with respect to wound discharge. Significantly more patients with mattress suture had wound dehiscence than in subcuticular sutures $(14.8 \%$ versus $5.5 \%)$. Similar observations were made by Vasudev et al. The rate of infection and resuturing was more in mattress group than in subcuticular group, $40.7 \%$ versus $18.5 \%$ and $21.2 \%$ versus $7.4 \%$ respectively. Choudhary et al had made similar observations in their study titled "comparison of wound outcomes with mattress sutures and subcuticular sutures". 8 
Pain at operated site on postoperative day 3-7 was significantly more in patients with mattress sutures than with subcuticular sutures and is statistically significant in this study. Probably due to multiple skin and subcutaneous tissue pricks and a greater number of suture knots during mattress suturing, patients experience more pain in postoperative period.

Among the secondary outcomes in this study, cosmetic appearance and patient satisfaction about scar was better in subcuticular than in mattress sutures. However, both groups had similar pain score at 6 weeks. Vasudev et al had made similar observations in their study on subcuticular versus mattress skin closure techniques following obstetrics and gynecology laparotomies by low transverseincision. ${ }^{14}$ Even in their study, wound edge approximation alone was clearly poor with mattress sutures which were evidenced by increased superficial wound dehiscence.

In a large systematic review of Cochrane database, Guruswamy et al compared continuous versus interrupted skin sutures for non-obstetric surgeries and found that superficial wound dehiscence may be reduced by using continuous subcuticular sutures. ${ }^{11}$ In the present study, very few women had wound gaping and needed resuturing in subcuticular group than in mattress group. But, mattress sutures being interrupted skin closure technique provides better route for drainage of subcutaneous collection which is beneficial women.

Subcuticular sutures have better approximation of skin edges and thus contribute for satisfaction by the patients. Tanaka et al observed that patients preferred subcuticular closure technique, citing better cosmetic results and less pain. ${ }^{17}$

Abdominal closure after surgery should not only aim at restoring anatomy and function but also look neat, appealing and leave cosmetically acceptable scars. Authors found continuous subcuticular sutures with delayed absorbable material for closure of Pfannensteil incision has the advantage of better wound edge approximation, less wound infection rates, lesser chances of wound dehiscence, less pain in immediate postoperative period and also cosmetically appealing scar and better patient satisfaction. However, pain after 6 weeks was similar in both groups. However, there were more women with previous caesarean sections in mattress suture group which could have contributed to a greater number of wound dehiscence and resuturing in that group.

The major limitation of this study is that it is an observational study, and there was selection bias as obstetricians opted for mattress sutures in obese women and in women with repeat caesarean section. Also, sample size in this study was small. Lastly, the study was of short duration (6 weeks) and authors did not assess the scar maturation over the long-term.

\section{CONCLUSION}

To a large extent, the suture material and technique used for skin wound closure determine the wound outcome and scar appearance. In today's era, cosmesis is an important aspect, cosmetically appealing scars give satisfaction to both patient and obstetrician. Several methods of skin closure are available to close the skin incisions like mattress sutures, subcuticular sutures, staples, glue adhesives. Subcuticular suture requires more technical expertise, more training, finer surgical skills, costlier suture materials but have superior long-term cosmetic outcome and better patient compliance. While mattress suture is easier, needs less training, less surgical skills and cheaper suture materials but can cause thicker scars and more pain in immediate postoperative period. However, mattress suture still remains a good choice in obese women, as it allows for drainage of subcutaneous collection.

Based on this observation, authors conclude that Pfannensteil incision closure with subcuticular sutures leads to less postoperative pain, better wound healing and cosmetic appearance when compared to mattress sutures with no significant difference at pain level at 6 weeks.

\section{Funding: No funding sources}

Conflict of interest: None declared

Ethical approval: The study was approved by the Institutional Ethics Committee

\section{REFERENCES}

1. Akolekar R. Surgical techniques for caesarean delivery. The caesarean birth. $1^{\text {st }}$ edition. Chapter 6: 1991.

2. Hema KR, Johanson R. Techniques for performing caesarean section. Best Pract Res Clin Obstet Gynaecol. 2001;15(1):17-47.

3. Wylie BJ, Gilbert S, Landon MB, Spong CY, Rouse DJ, Leveno KJ, et al. Comparison of transverse and vertical skin incision for emergency cesarean delivery. Obstet Gynecol. 2010;115(6):1134-40.

4. Altman AD, Allen VM, McNeil SA, Dempster J. Pfannenstiel incision closure: a review of current skin closure techniques. J Obstet Gynecol Canada. 2009;31(6):514-20.

5. Ramsey PS, White AM, Guinn DA, Lu GC, Ramin SM, Davies JK, et al. Subcutaneous tissue reapproximation, alone or in combination with drain, in obese women undergoing cesarean delivery. Obstet Gynecol. 2005;105:967-73.

6. Tuuli MG Rampersad RM, Carbone JF, Stamilio D, Macones GA, Odibo AO. Staples compared with subcuticular suture for skin closure after cesarean delivery: a systemic review and meta analysis. Obstet Gynecol. 2011;117(3):682-90.

7. Walter JB, Israel MS. Wound healing, Textbook of general pathlogy, $6^{\text {th }}$ ed. Ch.9:124-5. 
8. Choudhary A, Bansal N, Chaudhari P. Closure of pfannenstiel skin incisions in cesarean sections: comparison of wound outcomes with interrupted mattress vs. subcuticular suture. Int $\mathbf{J}$ Reprod Contracept Obstet Gynecol. 2017;6:2964-8.

9. Mackeen AD, Berghella V, Larsen ML, Techniques and materials for skin closure in caesarean section. Cochrane Database Syst Rev. 2012;11:CD003577.

10. Clay FS, Walsh CA, Walsh SR. Staples vs. subcuticular sutures for skin closure at cesarean delivery: a metaanalysis of randomized controlled trials. Am J Obstetric Gynecol. 2011;204(5):378-83.

11. Guruswamy KS, Toon CD, Allen VB, Davidson BR. Continous versus intrupted sutures for non-obstetric surgery. Cochrane Database Syst Rev. 2014;142:CD010365.

12. Alderdice F, McKenna D, Dornan J. Techniques and materials for skin closure in caesarean section. Cochrane Data Syst Rev. 2003;2:CD003577.

13. Kudur MH, Pai SB, Sripathi H, Prabhu S. Sutures and suturing techniques in skin closure. Indian $\mathbf{J}$ Dermatol Venereol Leprol. 2009;75:425-34.

14. Akhila V, Vidhyashree GP, Shantala R, Jyothi S, Pratap K. Subcuticular versus mattress skin closure techniques following OBGYN laparotomies by low transverse incision. IOSR J Pharma. 2016;6(11):426.
15. Nguyen DT, Orgill DP, Murphy GF. Chapter 4: pathophysiologic basis for wound healing and cutaneous regeneration. biomaterials for treating skin loss. Woodhead Publishing (UK/Europe) and CRC Press (US), Cambridge/Boca Raton; 2009:25-57.

16. Hawker GA, Mian S, Kendzerska T, French M. Measures of adult pain: Visual Analog Scale for Pain (VAS pain), numeric rating scale for pain (NRS pain), McGill pain questionnaire (MPQ), short-form McGill pain questionnaire (SF-MPQ), chronic pain grade scale (CPGS), short form-36 bodily pain scale (SF-36 BPS), and measure of intermittent and constant osteoarthritis pain (ICOAP) arthritis care and research. 2011;63(11):S240-S252.

17. Tanaka A, Sadahiro S, Suzuki T, Okada K, Saito G. Randomized controlled trial comparing subcuticular absorbable suture with conventional interrupted suture for wound closure at elective operation of colon cancer. Surg. 2014;155(3):486-92.

Cite this article as: Shridevi AS, Bhovi MR, Prabhudeva P, Renuka, Maitra C. Which is better for pfannensteil skin incision closure in caesarean section? Interrupted mattress suture or continuous subcuticular suture. Int J Reprod Contracept Obstet Gynecol 2020;9:3711-7. 